\title{
Epidemics of syphilis in the newly independent states of the former Soviet Union
}

Economic and social disruption and wars often coincide with epidemics of infectious disease. It is now clear that since the early 1990s the newly independent states (NIS) of the former Soviet Union have experienced major epidemics of sexually transmitted disease (STD), especially of syphilis. ${ }^{12}$ Table 1, based on data held by the World Health Organisation Regional Office for Europe, illustrates the scale of the problem. For instance, by 1996 rates of syphilis notification in the Russian Federation had risen to 263 per 100000 total population, a 48-fold increase over 1989 levels. Roughly equal numbers of men and women were affected, with the bulk of cases classified as infectious forms. These rates obscure even higher levels of infection among younger people: in 1996 the rate of notification of new cases of syphilis in young women aged 18-19 in Russia exceeded one per $100{ }^{1}$ Estimated incidence of syphilis in western European countries remains below 10 per 100000 although cases of syphilis which are linked to infection acquired in the NIS are being reported in these countries.

These epidemics may have important implications for the continent as a whole, in terms of the human suffering associated with both acute infection, and the sequelae of longer term infection. But there is also increasing evidence that they may be an important factor in significantly enhancing the transmission of human immunodeficiency virus (HIV). ${ }^{3}$ Therefore, a conjunction of high STD prevalence with the rapidly escalating epidemics of injecting drug use and drug related HIV transmission ${ }^{4}$ threatens to generate epidemics of sexually acquired HIV infection which far outstrip those encountered in most western European countries. If these do occur they may have a profound negative influence on HIV occurrence in Europe as a whole.

Why have these syphilis epidemics occurred? Rates of bacterial STD occurrence are largely determined by sexual behaviour on the one hand and by the accessibility, acceptability, and effectiveness of services for early diagnosis and treatment on the other. Both are likely to have been radically altered by recent economic and political changes

Table 1 Rates of notification of new cases of syphilis in the newly Table 1 Rates of
independent states

\begin{tabular}{lcccccrr}
\hline \multicolumn{7}{c}{$\begin{array}{l}\text { Notification rates of new cases of syphilis (per } 100 \\
\text { population) }\end{array}$} & \multicolumn{1}{l}{ 000 } \\
\cline { 2 - 8 } & 1990 & 1991 & 1992 & 1993 & 1994 & 1995 & 1996 \\
\hline Armenia & 3.7 & 7.1 & 9.0 & 9.8 & 12 & 12 & \\
Azerbaijan & 2.7 & 4.0 & 6.0 & 7.8 & & & \\
Belarus & 2.7 & 5.1 & 12 & 31 & 72 & 149 & 210 \\
Estonia & 3.4 & 7.4 & 11 & 23 & 57 & 70 & 70 \\
Georgia & 13 & 13 & 13 & 12 & 16 & 16 & \\
Kazakhstan & 1.5 & 2.1 & 3.5 & 8.2 & 33 & 123 & 231 \\
Kyrgyzstan & 2.0 & 2.1 & 2.5 & 4.4 & 22 & 33 & 137 \\
Latvia & 4.8 & 8.1 & 10 & 32 & 59 & 91 & 117 \\
Lithuania & 2.5 & 7.0 & 10 & 18 & 59 & 87 & 99 \\
Moldova & 16 & 20 & 47 & 83.3 & 116 & 173 & 200 \\
Russian Fed & 5.4 & 7.2 & 13 & 34 & 86 & 172 & 263 \\
Tajikistan & 1.6 & 1.6 & 2.9 & 5.8 & 8.3 & 20 & 12 \\
Turkmenistan & 4.6 & 5.4 & 6.3 & 8.3 & 15 & 23 & 28 \\
Ukraine & 6.0 & 10 & 18 & 35 & 69 & 119 & 144 \\
Uzbekistan & 1.8 & 1.9 & 2.5 & 4.4 & 11 & 25 & 24 \\
\hline & & & & & & & \\
\hline
\end{tabular}

which have generated huge income differentials and poverty, with rising unemployment, especially among women. ${ }^{56}$ The opening of borders has increased migration both within the region and between the region and other countries.

Although systematic studies of changes in sexual behaviour are few, sociologists speak of a general casualisation of sexual relationships and, in some countries, a rapid growth in formal and informal prostitution together with earlier sexual debut (Professor Valeriy Cherviakov, personal communication). Increasing cultural commerce between East and West has led to a rapid penetration of sexually oriented products, images, and advertising. Pornography has become widely available through sex shops and other outlets. The emphasis on individual choice and consumerism, the glamorisation of sexuality and the diffusion of sexual imagery may thus have led to a profound shift in sexual mores and lifestyles especially among young people.

Declining gross domestic product in several countries has undermined governments' resource bases for funding health services and other elements of social infrastructure. ${ }^{7}$ Historically, the system of STD control in the USSR was based in a centrally controlled nationwide clinical dermatovenereology service (DVS). ${ }^{8}$ The DVS offered free diagnosis and treatment, with frequently used legal sanctions to force those infected to undergo treatment and to identify sexual contacts for tracing. It was not guaranteed that the names of infected people would not be passed to other government agencies and employers. In addition, there was an extensive programme of active screening and case finding in clinically and occupationally defined groups. Diagnostic testing was reasonably well validated although standard treatment of syphilis required hospitalisation and prolonged treatment with penicillin injections. Surveillance of STDs was achieved through mandatory universal notification by physicians of newly identified cases.

In post-Soviet NIS the old DVS structures have largely survived but with major changes. In response to increasing unwillingness among patients to suffer stigma and sanctions, and to the failure of government to pay for services, in several countries DVSs have developed a large number of parallel anonymous dermatovenereology clinics (ADVCs) ${ }^{1}$ at which people can seek anonymous testing for STD ${ }^{8}$ But they have to pay. The cost for investigation and treatment of syphilis may exceed $\$$ US200. Services use the income to substitute for unpaid government funding. In reality the levels of confidentiality in ADVCs may be very poor, and while these clinics may offer modern outpatient treatment for syphilis with benzathine penicillin, in some regions up to $50 \%$ of patients are still managed in hospital as inpatients. The ADVCs usually operate on a fee for service basis in which each item is costed and charged directly to the patient. Which diagnostic tests are performed, and which treatment is prescribed are thus determined to a large extent by the patient's ability or willingness to pay. This leads to wide variation in the quality of the clinical service received. For example, among paying patients, testing and vigorous treatment for ureaplasmas and mycoplasmas is commonly carried out while those 
using the non-paying service may not be adequately screened for gonorrhoea.

Attempts have been made to move towards more integrated sexual health services. There has been collaboration with other sectors such as family planning and women's consultation centres. Projects designed to access and provide services to individuals (such as sex workers, homosexual men, and injecting drug users) at increased risk of STD are beginning to be designed and implemented. However, these continue to be hampered by de facto criminalisation of these groups, and the absence of the understanding between security forces and health authorities necessary to allow widespread effective work with these groups to be developed.

\section{Achieving control}

It would be tempting to see the problems of achieving effective STD control in Russia to be primarily technicalall that is needed is to modernise, with confidential patient management based on a more rational diagnostic approach, and modern techniques to access and target services and health promotion towards marginalised core groups-but this would be to ignore the realities. Responsible national authorities now recognise that control can only be achieved through combining sexual health promotion activities with the achievement of early detection and effective treatment of cases. They realise that the old approach, based upon legal sanctions, is no longer desirable or effective, and that early detection can only be achieved by providing confidential and affordable services which patients trust and which protect them from the negative social consequences of an STD diagnosis. This has been reinforced by a series of workshops organised by the WHO and UNAIDS which has achieved consensus among those responsible for DVS at the national level within the NIS countries, on priorities for the future development of services.

But to agree on priorities and to implement them are not the same thing. The actual development of services is being driven by competing forces. Firstly, the desire to modernise and to respond rationally and effectively to the epidemics. Secondly, the need to generate income in order to keep the service running, which drives the service towards activities for which patients can be charged and away from likely more cost effective activities in health promotion and patient care. Thirdly, there is an ideological hangover within the DVS which means that the interests of the individual are seen as secondary to the needs of society as a whole, and this is used to justify the often insensitive way in which people are treated, as well as the lack of confidentiality which still characterises much of the service. An effective strategy to achieve the control of STDs in the NIS will therefore need to find ways to modify these forces and the way they interact, in order to drive the development of control interventions towards the technical shape which all our experience suggests will be effective.

A recent WHO sponsored meeting set up a task force to coordinate the activities of multilateral and bilateral organisations in developing a strategy to provide support to NIS in STD control. This will need support from all interested parties, in particular from the European Union. In addition, our own sexual health professionals, agencies, and research groups should consider whether they could make a contribution through the development of exchange programmes and training activities, and through collaboration in demonstration projects. These should focus not only on technical aspects of interventions and the sharing of experience of working in the field with young people, homosexual men, and sex workers, but also on ethical issues, the principles and practice of confidentiality, and putting into place the foundations of doctor-patient relationships based on trust, confidence, and mutual respect.

A M RENTON

Department of Social Science and Medicine, Imperial College of Science Technology and Medicine, London

Russian Association against STD (SANAM),

K K BORISENKO Moscow, Russian Federation

Department of Epidemiology and Community Medicine, A MEHEUS Universitaire Instelling Antwerpen, Belgium

A GROMYKO

World Health Organisation Regional Office for Europe, Copenhagen, Denmark

1 Tichonova L, Borisenko K, Ward H, et al. Epidemics of syphilis in the Russian Federation: trends, origins and priorities for control. Lancet 1997;350:210-13.

2 Linglof T. Rapid increase of syphilis and gonorrhoea in parts of the former USSR. Sex Transm Dis 1995;22:160-1.

3 Grosskurth H, Mosha F, Todd J, et al. Impact of improved treatment of sexually transmitted diseases on HIV infection in rural Tanzania: randomised controlled trial. Lancet 1995;346:530-6.

4 Hamers FF, Batter V, Downs AM, et al. The HIV epidemic associated with injecting drug use in Europe: geographic and time trends. AIDS 1997;11: injecting

5 Gaspard M. Incomes and living standards in central and eastern Europe and the former Soviet Republics. Paper presented at the NATO economic colloquium on economic developments in cooperation partner countries from a sectoral perspective. Brussels, 30 June-2 July 1993

6 Gimpelson V. Labour market and employment in Russia: beginning of changes. Paper presented at the NATO economic colloquium on economic developments in cooperation partner countries from a sectoral perspective. Brussels, 30 June-2 July 1993.

7 The Economist Intelligence Unit: Country Report: Russian Federation fourth quarter 1995

8 Control over Sexually Transmitted Diseases; Order No 286. Moscow: Ministry of Health of the Russian Federation, 1993. 